\section{“A GENTE TEM QUE SOMAR": FONTES DE CAPTAÇÃO FINANCEIRA DE ATLETAS DA SELEÇÃO BRASILEIRA DE JUDÔ}

\author{
"WE HAVE TO ADD": FUNDING SOURCES FOR ATHLETES OF BRAZIL'S \\ NATIONAL JUDO TEAM C P
}
"TENEMOS QUE SUMAR": FUENTES DE CAPTACIÓN FINANCIERA DE LOS DEPORTISTAS DE LA SELECCIÓN BRASILEÑA DE JUDO C

doi' https://doi.org/10.22456/1982-8918.112306

Fabiana Della Giustina dos Reis* <bia.dellagr@gmail.com>

André Mendes Capraro* <andrecapraro@gmail.com>

*Universidade Federal do Paraná. Curitiba, PR, Brasil.
Resumo: O judô é um esporte em destaque no Brasil. Um dos motivos para isso é o suporte financeiro que o país oferta. Por conta disso, este trabalho objetivou descrever e analisar as formas de captação de recursos financeiros dos atletas de ponta do judô e detalhar a utilização do Programa Bolsa Atleta em suas carreiras. Foram entrevistados 17 atletas da seleção brasileira de judô. Geralmente, os atletas se beneficiam de quatro fontes de recursos financeiros - clube, patrocínios individuais, Programa de Atletas do Alto Rendimento (PAAR) e Programa Bolsa Atleta. Além disso, a Confederação Brasileira de Judô (CBJ) auxilia com outros recursos. Concluiu-se, então, que as principais fontes de financiamento dos atletas vêm do governo federal. É possível se manter financeiramente como atleta de alto rendimento, contudo, há um déficit no financiamento de judocas de base, falta de suporte para recuperação de lesões e para o pós-carreira do atleta.

Palavras chave: Artes marciais. Desempenho atlético. Atletas profissionais. Financiamento de capital.
Recebido em: 19 mar. 2021 Aprovado em: 10 jun. 2021 Publicado em: 27 jul. 2021

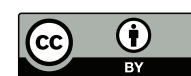

Este é um artigo publicado sob a licença Creative Commons Atribuição 4.0 Internacional (CC BY 4.0). eISSN: $1982-8918$ 


\section{INTRODUÇÃO}

O judô é um dos esportes mais conhecidos e praticados no Brasil (QUEIROZ et al., 2020). É, também, a modalidade que mais trouxe medalhas olímpicas para o país (REIS; CAPRARO, 2020). Com isso, ele é considerado um exemplo de sucesso esportivo internacional (MAZZEI, 2015). Um dos fatores para alcançar este status é o suporte financeiro que o país oferta (DE BOSSCHER et al., 2006). Um estudo realizado por De Bosscher et al. (2015) comparou os nove pilares ${ }^{1}$ que levam ao sucesso esportivo em 15 países $^{2}$. Dentre eles, o Brasil é o terceiro país que mais investe financeiramente no esporte, atrás da França e da Coreia do Sul.

O apoio governamental do Brasil para esta área vem desde a década de 1980 (TUBINO, 1993). A partir desse momento, o esporte passou a ser um compromisso oficial do governo - desde o esporte de participação até o alto rendimento (OLIVEIRA; BORTOLETO, 2012). Contudo, de acordo com Guimarães (2017), o derradeiro impacto para as políticas públicas esportivas veio a partir da década de 2000 , após a criação do Ministério Extraordinário do Esporte ${ }^{3}$. Dentre as leis criadas, a Lei AgneloPiva e a Lei de Incentivo ao Esporte (LIE) se destacaram por beneficiar clubes e confederações. A primeira, a qual é uma alteração da Lei 9.615 (Lei Pelé), tem como principal mudança destinar $2 \%$ da arrecadação das loterias federais ao Comitê Olímpico Brasileiro (COB) e ao Comitê Paralímpico Brasileiro (CPB) (MORAES E SILVA et al., 2014). Já a segunda possibilita que pessoas físicas e jurídicas possam descontar até $6 \%$ do Imposto de Renda a partir de patrocínio ou doação para projetos esportivos (BUENO, 2008).

Nesse cenário, destaque ainda maior se dá para o Programa Bolsa Atleta, pois este fornece o financiamento diretamente ao atleta, por meio de um repasse mensal fixo (MORAES E SILVA et al., 2014). Este Programa, criado no ano de 2004, busca abranger todas as etapas do alto rendimento, dando suporte a atletas de base até os mais bem colocados no ranking mundial. Para isso, o sistema oferta seis categorias de bolsa: Base ( $\mathrm{R} \$ 370,00)$; Estudantil ( $\mathrm{R} \$ 370,00)$; Nacional $(\mathrm{R} \$ 925,00)$; Internacional ( $R$ \$ 1.850,00); Olímpica/Paralímpica ( $R \$ 3.100,00)$; e Pódio (de $R \$$ $5.000,00$ até $\mathrm{R} \$ 15.000,00$ ) (DIAS et al., 2016). Esta última categoria oferece o valor do subsídio de acordo com a posição que o atleta se encontra no ranking mundial da modalidade, podendo ser contemplado aquele que se encontra até a $20^{a}$ colocação (CORRÊA et al., 2014).

Dentro do Bolsa Atleta, o judô foi uma das modalidades que mais obteve atletas contemplados desde o surgimento do programa (CAMARGO et al., 2020). Percebe-se, então, que o financiamento esportivo para o atleta é um tema discutido tanto na agenda governamental (OLIVEIRA; BORTOLETO, 2012) quanto na literatura (DE BOSSCHER et al., 2006, 2009; DIGEL, 2002; GREEN; HOULIHAN, 2005).

\footnotetext{
1 Suporte financeiro; governança, estrutura e organização; esporte de participação; identificação de talentos; suporte atlético e pós-carreira; instalações de treinamento; treinamento de técnicos; competições (inter)nacionais; pesquisa científica e inovação no esporte.

2 Austrália, Brasil, Canadá, Dinamarca, Estônia, Finlândia, Bélgica, França, Japão, Holanda, Irlanda do Norte, Portugal, Espanha, Coreia do Sul e Suíça.

3 Isso teve alterações em 2019, quando o Ministério do Esporte foi extinto e deu lugar à Secretaria Especial do Esporte, que a partir de então teve constantes trocas de comando. Considera-se que isso pode gerar instabilidade relacionada às políticas esportivas.
} 
Com isso, a percepção dos atletas que alcançaram as melhores colocações a nível internacional auxilia a entender o desenvolvimento do esporte a partir do suporte financeiro. Sendo assim, este trabalho objetivou descrever e analisar as formas de captação de recursos financeiros dos atletas de ponta do judô e detalhar a utilização do Programa Bolsa Atleta em suas carreiras.

\section{CAMINHOS METODOLÓGICOS}

Para alcançar o objetivo proposto, foram realizadas entrevistas semiestruturadas (GIL, 2008) com 17 atletas da seleção brasileira de judô. As perguntas foram elaboradas pelos autores e, em seguida, enviadas a um grupo focal para ajustes. Como critério de inclusão, foram selecionados judocas contemplados pelo Bolsa Atleta categoria Pódio pelo menos uma vez entre os anos de 2018 e $2019^{4}$.

O contato com os atletas se deu a partir do suporte da Confederação Brasileira de Judô (CBJ), a qual foi contatada por meio do projeto de pesquisa Inteligência Esportiva $^{5}$. As entrevistas ocorreram durante o campeonato internacional Grand Slam em Brasília (DF), entre os dias 06 e 08 de outubro de 2019. Os atletas, em conjunto com a CBJ, definiram o momento das entrevistas, sendo que elas ocorreram, majoritariamente, após o término da participação específica de cada atleta na competição. As entrevistas foram gravadas com o celular de um dos pesquisadores. O tempo médio foi de 13 minutos e 9 segundos.

Aos atletas foi entregue um Termo de Consentimento Livre e Esclarecido $(\mathrm{TCLE})^{6}$, no qual puderam solicitar o anonimato. Dentre eles, apenas um optou por ocultar sua identidade, neste sentido, ele será indicado como "entrevistado anônimo". Os colaboradores estão indicados no Quadro 1, juntamente com a categoria de peso em que competem:

Quadro 1 - Judocas entrevistados

\begin{tabular}{|l|c|l|c|}
\hline Nome & $\begin{array}{c}\text { Categoria } \\
\text { de peso }\end{array}$ & Nome & $\begin{array}{c}\text { Categoria } \\
\text { de peso }\end{array}$ \\
\hline Beatriz Rodrigues de Souza & $+78 \mathrm{~kg}$ & Leonardo Ribeiro Gonçalves & $-100 \mathrm{~kg}$ \\
\hline Daniel Borges Cargnin & $-66 \mathrm{~kg}$ & Marcelo Garcia Contini & $-73 \mathrm{~kg}$ \\
\hline David Moura Pereira da Silva & $+100 \mathrm{~kg}$ & Maria de Lourdes Mazzoleni Portela & $-70 \mathrm{~kg}$ \\
\hline Eduardo Yudy Brito Santos & $-81 \mathrm{~kg}$ & Maria Suelen Altheman & $+78 \mathrm{~kg}$ \\
\hline Eleudis de Souza Valentim & $-52 \mathrm{~kg}$ & Rafael Augusto Buzacarini & $-100 \mathrm{~kg}$ \\
\hline Entrevistado anônimo & $\mathrm{XXX}$ & Rafael Godoy Macedo & $-90 \mathrm{~kg}$ \\
\hline Eric Gomes Takabatake & $-60 \mathrm{~kg}$ & Rafaela Lopes Silva & $-57 \mathrm{~kg}$ \\
\hline Ketleyn Lima Quadros & $-57 \mathrm{~kg}$ & Victor Rodrigues Penalber de Oliveira & $-81 \mathrm{~kg}$ \\
\hline Larissa Cincinato Pimenta & $-52 \mathrm{~kg}$ & & \\
\hline
\end{tabular}

Fonte: dados da pesquisa.

\footnotetext{
4 Os editais de 2020 e 2021 repetiram os atletas contemplados de 2019 por conta da pandemia da Covid-19, isso porque as modalidades não tiveram sua agenda de competições.

5 Uma parceria da Universidade Federal do Paraná com o antigo Ministério do Esporte.

6 Aprovado pelo Comitê de Ética do Instituto de Ciências Humanas da Universidade de Brasília sob o número CAAE 51225615.5.0000.5540.
} 
Após as entrevistas, as narrativas passaram por um processo de transcrição em sua íntegra para facilitar o processo de leitura, a partir dos preceitos de Verena Alberti (2008). Para análise dos resultados, esta pesquisa apropriou-se da metodologia de análise de conteúdo (AC), proposta por Bardin (1977). Isto porque esta permite uma abordagem tanto quantitativa quanto qualitativa (CAREGNATO; MUTTI, 2006). Este recurso permite uma compreensão ampla sobre determinado assunto. Além disso, foi utilizado o software Nvivo para análise qualitativa das entrevistas, o qual é um dos mais utilizados por esta metodologia (LAGE, 2011). Com ele, foi realizado uma nuvem de palavras a partir das falas dos judocas. Por fim, as narrativas foram separadas em duas categorias de acordo com as suas temáticas, procedimento sugerido pela própria AC. A primeira parte tratou das formas de captação de recursos dos atletas, e a segunda deu enfoque no Bolsa Atleta Pódio.

\section{FONTES DE CAPTAÇÃO: "NÃO SÃO TODOS QUE RECEBEM UM VALOR ALTO"}

[...] o atleta, se ele receber só de uma fonte, fica muito difícil. O que eu quero dizer com isso? Se eu receber só do meu clube, o Esporte Clube Pinheiros, ia ser realmente complicado, mas a gente tem que somar. [...] somando tudo, ainda mais quando eu estava no Bolsa [Atleta] Pódio eu conseguia viver de certa maneira bem e suprir tudo o que eu necessito para ser um atleta de alto rendimento dentro do país (MARCELO CONTINI, Diário de Campo).

A partir da fala de Marcelo Contini, percebe-se que há variadas fontes de recurso para os atletas de judô no Brasil. A forma de subsídio mais tradicional é aquela advinda dos clubes. Este auxílio foi reportado, também, pelos atletas que defendem o Esporte Clube Pinheiros (7), a Sociedade de Ginástica de Porto Alegre (Sogipa) (5), e o Clube Paineras do Morumby (1). Contudo, este financiamento não os acompanha desde o início de suas trajetórias esportivas. Os entrevistados alegaram receber benefícios de suas agremiações a partir do momento que alcançaram bons resultados. Eric Takabatake explica melhor:

[...] hoje em dia eu acredito que atletas de ponta, quando falo de ponta é seleção, depende do clube se ganha um dinheiro bom. [...] eu conheço muitos atletas bons que às vezes têm que dividir o tatame com o trabalho por causa disso. Porque às vezes, como eu falei, não são todos que recebem um valor alto nos clubes, só atletas de ponta mesmo (ERIC TAKABATAKE, Diário de Campo).

De acordo com Larissa Pimenta, a partir do momento em que o atleta alcança tais resultados, ele é contratado por um clube, recebendo um valor mensal. Os atletas que representam o Instituto Reação (4) não recebem o mesmo benefício. Isto ocorre porque o instituto não é um clube privado, como os outros, e sim uma Organização de Sociedade $\mathrm{Civil}^{7}$ (INSTITUTO REAÇÃO, 2020). Portanto, por mais que a instituição não oferte um salário fixo a seus representantes, a agremiação criou uma alternativa para auxiliar os judocas. De acordo com narrativas, os atletas recebem patrocínio financeiro de patrocinadores do Instituto Reação. David Moura alega: "É uma forma que a gente fez de aliviar o [Instituto] Reação, mas eu recebo muito bem pelo patrocínio que cobre isso" (DAVID MOURA, Diário de Campo).

7 Instituição privada sem fins lucrativos, que presta um serviço com finalidade social. Disponível em: http://www. planalto.gov.br/ccivil_03/_ato2015-2018/2015/lei//13204.htm 
O auxílio mensal ao judoca se torna possível por conta da arrecadação dos clubes pela LIE. Com exceção da Sogipa, todos os clubes representados pelos entrevistados se localizam na região sudeste do Brasil, área que concentra $82 \%$ da arrecadação da LIE. A região sul, local que se encontra a Sogipa, vem em segundo lugar com $10 \%$ da captação econômica. Além disso, o Esporte Clube Pinheiros é o maior clube esportivo da América Latina e foi a entidade que mais se beneficiou deste recurso (MATIAS et al., 2015). Neste sentido, Rafael Macedo ressalta a importância do investimento estatal nos clubes:

[...] os clubes dependem bastante do governo normalmente. Nem todos os clubes têm uma condição financeira tão grande, nem todos os clubes estão dispostos. Porque, aqui no Brasil, os clubes fortes são clubes de lazer. Você vê que o pessoal associado é para pegar piscina, uma coisa de família, então eles não podem gastar tanto dinheiro com os atletas, então dependem muito do governo (RAFAEL MACEDO, Diário de campo).

De acordo com a literatura, o judô no Brasil é fomentado a partir de clubes esportivos, embora também se desenvolva a partir de projetos socioesportivos (QUEIROZ et al., 2020). Tal afirmativa corrobora com os resultados da pesquisa, tendo em vista que as instituições que dão suporte aos judocas entrevistados são três clubes privados e um socioesportivo.

Além do benefício financeiro mensal, os clubes custeiam viagens para competições nacionais. De acordo com as narrativas, todas as instituições pagam passagens, hospedagem e alimentação para seus atletas. Para conseguir este benefício, o judoca passa por um processo seletivo:

\footnotetext{
O clube entra mais na questão da adesão, que são os atletas que... na verdade não é só querer ir viajar, há toda uma seleção para ver quem pode, quem não. Então eu acho que depende de clube para clube. Por exemplo, a Sogipa, que é meu clube, em véspera de olimpíada eles vão me apoiar no que eu precisar. Por exemplo, eu estou precisando de ponto "ah, vamos ver o que a gente pode fazer". Isso é muito bom, porque deixa um pouco mais confortável para poder treinar tranquilo. Saber que na hora que precisar, vai ter o apoio (DANIEL CARGNIN, Diário de Campo).
}

Pela fala, compreende-se que os atletas que disputam vaga olímpica recebem maiores benefícios de seus clubes. Neste sentido, Bueno (2008)define as três categorias de manifestação esportiva com as quais trabalha: esporte de alto rendimento, esporte educacional e esporte participativo. Igualmente apresenta a estrutura teórica a ser utilizada, a Advocacy Coalition Framework - ACF, que se utiliza de estrutura de crenças e valores formatada pelo autor para o estudo do campo esportivo, tratado pela ACF com um subsistema ou área específica de política publica. Procurando melhor embasar o estudo, a tese resgata os principais conceitos históricos e sociológicos relacionados ao campo do esporte e reforça a interação deste com os aspectos sociais, econômicos e políticos. Em seguida, aborda a gênese do esporte e sua vinda ao Brasil, no início do século passado, passando pela criação das entidades desportivas e apresentando as razões de seus conflitos de interesses. Ainda nesta parte, aborda a discussão sobre os valores e contra valores que permearam a discussão entre intelectuais a favor e contra o desenvolvimento do esporte. No período do Estado Novo a tese discute as razões que levaram o Estado a intervir no setor esportivo e a estruturá-lo institucionalmente com o Decreto 
Lei 3.199, de 1941. Com já apontado por outros autores, este decreto representou acentuada ação do Estado em favor do esporte de alto rendimento, fortalecendo propositadamente sua coalizão de atore, aqui chamada de pró-EAR, bem como reflete seu desejo de implementar valores higienistas e eugenistas que permeavam a sociedade intelectualizada de então. A tese aborda o caráter autoritário e corporativista do Decreto e como estas características foram usadas no período populistas para desenvolver bases clientelistas na estrutura formal do esporte. Na fase do regime militar, a tese discute o projeto de transformar o Brasil em uma potência olímpica nos moldes do futebol e como tal ideal determinou ação deliberada de incorporação do setor esportivo educacional aos princípios e valores do esporte de alto rendimento, o denominado como modelo piramidal. O estudo contempla a reação de parte da comunidade acadêmica e da prática educacional da área esportiva e também o surgimento do movimento do esporte para todos. O que é assumido pela tese como o início da coalizão contrária ao alto rendimento, aqui chamada de pró-EPE (esporte participativo e educacional alerta para a predominância de investimento no esporte de altíssimo rendimento. Por mais que o clube banque apenas as viagens para campeonatos nacionais, os atletas da seleção não ficam sem amparo em competições internacionais. Neste caso, a CBJ entra com auxílio para passagem, hospedagem e alimentação. Contudo, assim como ocorre com os clubes, a Confederação oferta suporte apenas para atletas convocados e selecionados:

É que têm regras, né? Você faz seletiva, entra dentro do processo. Eu, no caso, já estou dentro do processo, então eu tenho um aporte maior da seleção, então quanto mais eu vou rendendo, mais eu vou viajando. O clube não precisa pagar no momento, a não ser que, por exemplo, eu precise de determinados pontos para fechar minha posição no ranking, aí eu posso tentar pedir o suporte deles, ou eu mesmo posso ir lá e pagar uma competição, como eu já fiz esse ano. Eu fui para a Geórgia pagando do meu bolso (MARIA PORTELA, Diário de Campo).

Novamente, na fala da judoca, ficou latente o investimento dos clubes visando resultados no ranking e, consequentemente, vaga olímpica com a aproximação dos Jogos Olímpicos de Tóquio. Ademais, de acordo com a narrativa, quanto mais resultados o atleta conquista, mais a CBJ investe. Ou seja, atletas bem ranqueados conquistam subsídios para todas as viagens planejadas pela Confederação. Isso mostra que a CBJ trabalha com um sistema de recompensas, dando prioridade ao alto rendimento. Portanto, aqueles que não têm tantos resultados, ou estão iniciando no alto rendimento, precisam investir antes de ter o subsídio, como Larissa Pimenta explica:

[...] esse ano eu investi em duas competições, que foram dois Grand Prix. Eu tive vaga na seleção brasileira, eles dão as oportunidades, mas é claro que se você quer realmente chegar, você tem que investir. Eu gastei muito dinheiro, foram só duas viagens, mas como é internacional, né? Mas graças a Deus eu ganhei medalha nessas duas competições que eu fui aí o dinheiro voltou, ainda bem [risos]. [...] Eu fui e escolhi pagar minhas viagens, eu medalhei e conquistei uma viagem pela CBJ. Ela me deu viagem e assim foi, um investimento meu e depois da CBJ (LARISSA PIMENTA, Diário de Campo).

Além do suporte do clube e da Confederação em viagens, há também alguns serviços extras. Por exemplo, a CBJ oferta quimonos para os atletas em todas as 
competições para as quais são convocados, isto por causa do patrocínio concedido pela marca esportiva Mizuno. Já os clubes ofertam serviços e/ou profissionais especializados, como médicos, fisioterapeutas, nutricionistas, psicólogos, estrutura de treinamento físico em academia e, em alguns casos, plano de saúde. Assim como os clubes têm uma forma de captar recursos, a CBJ também tem uma maneira de obter financiamento. Como demonstrado na Tabela 1, em 2019, a entidade foi a segunda que mais arrecadou recursos através da Lei 13.756 - antiga Lei Agnelo-Piva (MORAES E SILVA et al. 2014). Além disso, por mais que a entidade tenha perdido o patrocínio da Petrobras e da Infraero após os Jogos Olímpicos do Rio de Janeiro 2016, atualmente ainda conta com o apoio do Bradesco, da Mizuno, da Scania, da Cielo, do SporTV e da Travel Ace Assistance (CBJ, 2020b).

Tabela 1 - Entidades que mais arrecadaram com a Lei 13.756 em 2019

\begin{tabular}{cc}
\hline Modalidade & Repasse 2019 \\
\hline Voleibol & $\mathrm{R} \$ 6.771 .599,38$ \\
Judô & $\mathrm{R} \$ 6.359 .926,08$ \\
Ginástica & $\mathrm{R} \$ 5.968 .034,13$ \\
Vela & $\mathrm{R} \$ 5.894 .303,66$ \\
Canoagem & $\mathrm{R} \$ 5.375 .700,44$ \\
Boxe & $\mathrm{R} \$ 5.289 .381,84$ \\
Atletismo & $\mathrm{R} \$ 5.250 .649,14$ \\
Tiro esportivo & $\mathrm{R} \$ 4.497 .021,41$ \\
Desportos aquáticos & $\mathrm{R} \$ 4.414 .991,07$ \\
Esgrima & $\mathrm{R} \$ 4.139 .988,88$ \\
\hline
\end{tabular}

Fonte: (COB, 2019).

Outra forma de financiamento dos judocas de alto rendimento no Brasil vem do Programa de Atletas do Alto Rendimento (PAAR). O Programa, criado em 2006 e consolidado em 2008, tem como objetivo fortalecer a equipe militar brasileira em eventos esportivos de alto rendimento, dentre eles os Jogos Militares Mundiais (SOUZA, 2017). Com isso, os atletas contratados recebem um valor entre $R \$ 1.500,00$ e $R \$ 4.500,00$ mensais, de acordo com seu ranqueamento (VARGAS; CAPRARO, 2020). Além disso, eles recebem os mesmos benefícios que um militar de carreira teria, como $13^{\circ}$ salário, férias, plano de saúde e uso das instalações esportivas militares (SOUZA, 2017).

Dentre os 17 entrevistados, 94,1\% foram beneficiados pelo PAAR; apenas o judoca Victor Penalber não recebeu tal suporte. Entretanto, quatro atletas deixaram de receber por exceder o limite máximo de oito anos (PICETSKEI et al., 2019), e 12 deles ainda são beneficiados por este programa. Os entrevistados enalteceram a importância do PAAR para a manutenção no esporte de alto rendimento. A efetividade do programa foi encontrada também na pesquisa de Vargas e Capraro (2020) com atletas da seleção brasileira de ginástica artística. Beatriz Souza explica como funciona essa parceria:

Você representa o Brasil em competições militares, tem eventos militares também que você participa. É simples, tranquilo, sabe? Não tem tanta... tem 
uma certa exigência, mas não tão crítica quanto tem que estar no clube todo dia, como tem que estar no exército. Não, no exército se você estiver no clube treinando, dando resultados, é como se você estivesse lá todo dia no exército também cumprindo o seu papel (BEATRIZ SOUZA, Diário de Campo).

Os judocas comentaram também sobre a aquisição de patrocínios individuais. Contudo, como Leonardo Gonçalves alerta: "Falar em patrocínio [privado] no Brasil para atleta olímpico eu acho que é muito difícil. Desconheço alguém que tenha um patrocínio que ajude de verdade, financeiramente dizendo" (LEONARDO GONÇALVES, Diário de Campo). Dentre os patrocínios citados, há apoio material de loja de suplementos, produtos alimentares para dietas com restrição calórica, esparadrapos e serviços odontológicos e de coaching. Nesse sentido, a parceria funciona mais em um formato de permuta do que de patrocínio, no qual os contratantes trocam serviços que não sejam dinheiro.

Apenas 17,6\% (3) dos entrevistados comentaram receber algum patrocínio financeiro. Entre eles: a atleta Beatriz Souza, que afirmou receber patrocínio da bolsa do SOI (Solidariedade Olímpica Internacional), que é uma iniciativa do Comitê Olímpico Brasileiro (COB); Rafaela Silva, que é patrocinada pela marca esportiva Nike; e Davi Moura, que é beneficiado com patrocínio de cinco empresas privadas. O judoca, que reside em Cuiabá/MS, explica: "Eu sou muito privilegiado quanto a isso, pois sou de uma região carente de atletas. Eu tenho ótimos patrocinadores, ótimos patrocínios, estou há bastante tempo ganhando com parceiros duradouros" (DAVID MOURA, Diário de Campo). Ele afirma que, por não haver muitos atletas que conquistaram resultados expressivos em sua cidade, as empresas concentram o patrocínio nele.

Por mais que a CBJ conte com patrocinadores, percebe-se que o mesmo não ocorre com os próprios atletas, tendo em vista que apenas dois deles recebem auxílio de empresas privadas. Essa ausência de investimento pessoal faz com que, de modo geral, muitos atletas abandonem o esporte (ROCHA; SANTOS, 2010). Neste sentido, entende-se a importância do investimento governamental, assim como do Programa Bolsa Atleta, que visa patrocinar diretamente o atleta. Esse recurso estatal passou a ser a principal fonte de renda do atleta de judô, fazendo com que o judoca possa permanecer no esporte de alto rendimento.

\section{PROGRAMA BOLSA ATLETA: "DÁ ATÉ UMA MOTIVAÇÃO MELHOR PARA TREINAR"}

Pelo Programa ser um sistema que busca oferecer subsídios para os atletas desde a base, muitos se beneficiam com mais de uma categoria de bolsa. Dentre os 17 entrevistados, 82,4\% (14) foram contemplados com outras categorias. De acordo com suas próprias narrativas, este sistema os acompanha durante a evolução no esporte. Um exemplo é o caso do atleta Daniel Cargnin, que recebeu em 2011 a categoria base, em 2012 a estudantil, em 2013 e 2014 a nacional, entre 2015 e 2017 a internacional e, desde então, recebe a categoria pódio (BRASIL, 2020a). Isto é, o Programa Bolsa Atleta acompanhou sua trajetória esportiva no judô. Nesse sentido, o atleta comenta: 
Eu acho que o dinheiro da bolsa dá uma tranquilidade para treinar. Porque, como eu falei antes, o judô não é igual ao futebol, mas isso dá uma tranquilidade para poder investir em suplemento, quimono. Porque tem que estar sempre tudo novo, tudo limpo, faixa e quimono. No final, eu acho que o dinheiro do clube não supriria a questão para estar bem, se concentrar $100 \%$ no judô. Eu acho que isso dá uma tranquilidade para os atletas da seleção (DANIEL CARGNIN, Diário de Campo).

Assim como a narrativa de Daniel Cargnin, os demais atletas alegaram que puderam se dedicar exclusivamente ao judô após alcançar a vaga na seleção brasileira e, paralelamente, conquistar a Bolsa Atleta Pódio. Corroborando esta afirmativa, Rafaela Silva alega:

[...] o Bolsa [Atleta] Pódio é uma das maiores rendas para a maioria dos atletas da seleção brasileira de judô [...]. Tem muito atleta que a gente vê lá fora que faz faculdade, que trabalha, que é formado, e a gente tem esse privilégio de ter o Bolsa [Atleta] Pódio. A gente não precisar ir trabalhar no meio período, para uma faculdade conciliar com uma viagem ou com uma classificação olímpica (RAFAELA SILVA, Diário de Campo).

Eric Takabatake, que entrou na seleção brasileira de judô no mesmo ano que entrou em vigor a categoria Pódio (2013), afirma o quanto essa bolsa serviu de motivação para sua melhora esportiva:

\begin{abstract}
[...] todo mundo ficou sabendo dessa bolsa no ano que eu entrei [na seleção brasileira de judô]. Eu até me assustei com os valores, porque eram valores que 'pô' [expressão e gesto de grandeza]. Eu já cheguei a ganhar Bolsa Atleta, mas o valor da Bolsa [Atleta] Pódio era muito maior. Eu até me assustei e falei 'caramba, é tudo?'. Então dá até uma motivação boa, você fala 'se eu melhorar, se eu trouxer resultados, subo bem no ranking e ainda tenho esse benefício', dá até uma motivação melhor para treinar, para competir melhor. Eu acredito que foi, não só, mas um grande fator para a minha melhora, tanto nos treinos como nas competições (ERIC TAKABATAKE, Diário de Campo).
\end{abstract}

Essa visão é compartilhada também pelo atleta Francisco Barreto Jr., da ginástica artística, que afirma que a troca de categoria de bolsa é um dos principais fatores motivacionais (VARGAS; CAPRARO, 2020). Assim como a falta de patrocínio financeiro pode ser um fator de desistência, sua presença pode também ser um fator motivador. Essa afirmativa corrobora o estudo de Gorner et al. (2019), no qual demonstrou-se que os atletas de judô se sentiam mais motivados a praticar quando o esporte se tornava sua principal fonte de renda. A eficiência do Programa Bolsa Atleta foi citada por todos os entrevistados, tanto aqueles que receberam outras categorias de bolsa, quanto os que foram contemplados apenas com a Bolsa Atleta Pódio.

De acordo com as narrativas, por mais que os atletas recebam alguns benefícios, o gasto para se manter no alto rendimento é elevado. Foi visto que os judocas recebem viagens internacionais pagas quando convocados pela CBJ, quimono, infraestrutura com serviços como nutrólogo, fisioterapeuta, psicólogo. Entretanto, mesmo com esses benefícios, há outros gastos. Este custo encontrase detalhado na Figura 1. O tamanho da palavra varia de acordo com o número de citações, quanto mais vezes citada, maior é a palavra. As palavras maiores foram ditas mais de sete vezes, já as menores, no mínimo uma vez. 
Figura 1 - Nuvem de palavras mais citadas em relação ao gasto dos judocas

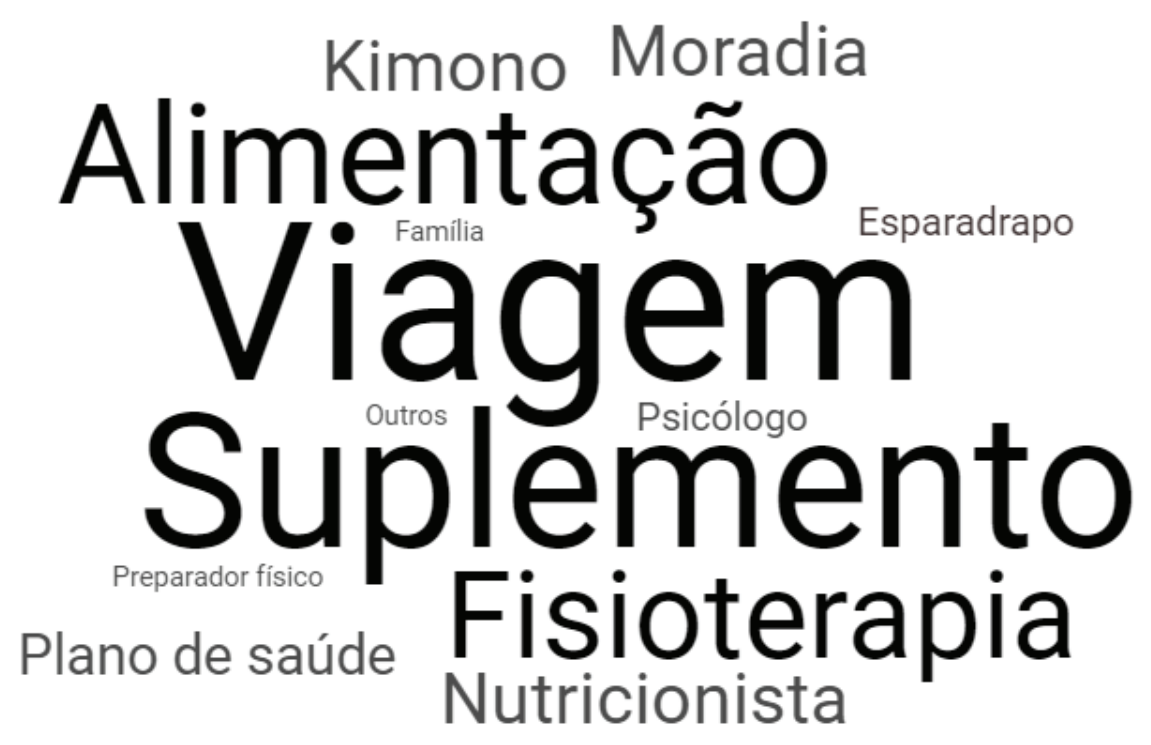

Fonte: dados da pesquisa

A partir da figura, percebe-se que o termo "viagem" foi o mais citado (15). Por mais que a CBJ financie viagens internacionais, os atletas não são convocados para todas. Há uma espécie de rodízio entre atletas, com exceção daqueles que estão nas primeiras colocações no ranking da Federação Internacional de Judô (FIJ) e têm maiores chances de medalhas. Com isso, percebe-se que os atletas necessitam investir em viagens a partir de seus próprios recursos. Essas são em forma de adesão, isto é, a CBJ fornece a documentação, repassa o custo total do gasto para o atleta e este paga o valor para a CBJ.

Além disso, os gastos com suplementação (11) e alimentação (8) foram muito citados. Principalmente em relação à primeira, as narrativas enfatizaram o alto custo para ingerir produtos de qualidade. Muitos autores apontam que suplementos alimentares são comumente utilizados por judocas de alto rendimento (KSIAŻŻEK et al., 2014; REDDY et al., 2002; STERKOWICZ et al., 2012). Isto porque o judô é um esporte de grande vigor físico, pois exige que os seus praticantes realizem esforços de alta intensidade intercalados por curtos períodos de recuperação (KRATZ et al., 2017). Com relação à alimentação, entende-se a importância relatada pelos atletas, tendo em vista que "[...] uma dieta correta é um dos fatores mais importantes que afetam as capacidades do exercício, otimizam os resultados do treinamento e aumentam a probabilidade de sucesso no esporte"8 (KSIAŻ̇̇EK et al., 2014, p. 37).

Os demais investimentos estão relacionados à performance e ao treinamento do atleta. Na Figura 1, há também a palavra "outros", nesta situação há o caso do atleta David Moura, que afirma: "Eu, por exemplo, pago uma casa onde moram cinco atletas para treinar comigo. Cada um deles recebe um pouco de dinheiro, o custo da casa eu pago e a alimentação diária deles" (DAVID MOURA, Diário de Campo). O judoca compete na categoria pesado $(+100 \mathrm{~kg})$, e alega não ter muitos atletas nessa categoria para poder treinar. Além dele, Leonardo Gonçalves e Rafael Buzacarini,

8 No original: "[...] a correct diet is one of the most important factors that affect exercise capabilities, optimise training outcomes and increase the likelihood of sport success". 
que competem na categoria meio-pesado $(-100 \mathrm{~kg})$, reforçam a necessidade de viajar para encontrar atletas para treinar.

Tendo em vista tais gastos com o esporte, os entrevistados alertaram sobre a preocupação em se manter no Bolsa Atleta Pódio. Isto porque a instabilidade do Programa (duração de 12 meses) gera insegurança nos atletas. A cada ano os judocas necessitam conquistar resultados em campeonatos internacionais para continuar bem ranqueados. Há, porém, alguns empecilhos citados que, muitas vezes, impedem o judoca de obter tais resultados. O primeiro deles é depender da convocação da CBJ para participar dos campeonatos. Para isto, o atleta precisa apresentar bons resultados, isto é, primeiro ele deve investir no esporte para, após isso, a CBJ investir nele. Outro fator comentado foi o risco de lesões. Neste sentido, Victor Penalber comenta sobre a condição financeira que o judô proporciona:

\begin{abstract}
É difícil. Na verdade, agora eu estou vivendo na outra ponta, porque no último ciclo olímpico eu estava muito bem, acabei ganhando as maiores bolsas, consegui patrocínio para o último ciclo olímpico no Rio. Nessa eu venho em um ciclo de muitas lesões, isso me fez cair no ranking. No momento eu até estou me sustentando muito com a ajuda dos meus pais, dos meus parentes que estão me auxiliando nesse momento. $\mathrm{O}$ atleta tem esse problema, ele vive de diferentes fases em que a parte financeira muda de uma hora para outra (VICTOR PENALBER, Diário de Campo).
\end{abstract}

Por conta das lesões, o atleta, que já conquistou o bronze no Campeonato Mundial de Judô de 2015, não pôde participar de muitas competições entre os anos de 2018 e 2019, perdendo o direito de pleitear o Bolsa Atleta Pódio. Além dele, outros atletas comentaram que tinham receio das lesões por ser um esporte de alto impacto e a falta de suporte nesses casos. O judô é considerado um esporte de combate com alto risco de lesão se comparado a outros como o caratê, o taekwondo e o jiujítsu (MACHADO; PLAPLER, 2019). Um estudo realizado por Pocecco et al. (2013) mostrou a incidência de lesões em diferentes níveis do judô e identificou que, dentre os atletas olímpicos participantes dos Jogos de 2008 e 2012, mais de $12 \%$ sofreram lesões. Neste sentido, Pinheiro et al. (2011) alertam sobre os riscos do atleta competir com lesão pela busca de resultados. Para isso, é importante criar alternativas para amparar o atleta que sofre lesão, para que este consiga retornar à prática de forma eficaz.

Outro ponto que os atletas alertaram no momento da entrevista sobre o Bolsa Atleta Pódio é a falta de aviso prévio para a abertura do edital. Isto foi mencionado como um fator negativo pelos atletas pela necessidade de tempo para organizar os documentos necessários. Contudo, este problema foi resolvido em agosto de 2020 , quando o Governo Federal anunciou que, a partir de 2021, os editais para pleitear a bolsa passariam a ser publicados sempre no mês de janeiro (BRASIL, 2020b).

Neste processo para pleitear o Bolsa Atleta Pódio, os entrevistados alegaram receber auxílio pleno da CBJ. Para as categorias inferiores de bolsa, os atletas afirmam que fazem o processo de pleitear o Bolsa Atleta por conta. Mesmo assim, de acordo com as narrativas, a CBJ, em parceria com a atual Secretaria Especial do Esporte, seleciona no máximo dois atletas de cada categoria entre os 20 ranqueados. David Moura comenta sobre este suporte da CBJ: 
Eu acho que no caso de todo mundo a Confederação tem ajudado muito, tem ficado atenta aos prazos, manda e-mail, pede documentação. A gente fornece documentação, mas é via CBJ, eu acredito que todo mundo é assim. O que facilita muito para a gente não ter que ficar pensando, se preocupando com data para não perder o prazo, que é uma coisa que para a gente é muito importante, o Bolsa Atleta Pódio. É realmente uma ajuda e tanto, no nosso desempenho, no nosso desenvolvimento, na qualidade de vida também que é comer bem, se alimentar bem, dormir bem, faz parte da vida do atleta (DAVID MOURA, Diário de Campo).

A relação da CBJ com os atletas foi comentada por todos como positiva. Os judocas mais velhos enfatizaram os avanços na gestão da CBJ e na relação com o atleta nos últimos anos. Isto pode ser explicado pelo fato de que entre os anos de 2005 a 2008 a CBJ passou por um processo de renovação de sua reputação administrativa (MAZZEl et al., 2012), pois em 1990 a CBJ havia sido condenada por irregularidade pelo Tribunal de Contas da União, conhecida como "Era Mamede", por ser presidida por Joaquim Mamede de Carvalho e Silva (1985-1990) e Joaquim Mamede de Carvalho e Silva Júnior (1991-2000) (CBJ, 2020a). Entretanto, na sequência, a CBJ passou a ser considerada um modelo de gestão esportiva (MAZZEI et al., 2012). Esta relação com a CBJ é importante para o atleta, pois o auxilia ao longo de sua trajetória. Contudo, é necessário um trabalho em conjunto da Confederação, do clube, do apoio governamental e privado para investir no atleta, fazendo com que este se motive a manter no esporte e trazer bons resultados para o país.

\section{CONSIDERAÇÕES FINAIS}

Este estudo teve como objetivo descrever as formas de captação de recursos financeiros dos atletas de ponta do judô. A partir da narrativa de 17 atletas, pôde-se observar que há diversas fontes de subsídio para judocas de alto rendimento no Brasil, e estes buscam se beneficiar do máximo possível. A primeira delas são os clubes que oferecem um salário, sobretudo para os atletas que compõem a seleção brasileira. Dentre as agremiações que os judocas representam, apenas uma não é privada, o Instituto Reação. Entende-se então a preferência de instituições privadas para fomentar o esporte de alto rendimento. Isto pode se dar pela oportunidade de o clube de divulgar seu nome e, também, arrecadar finanças a partir das Leis de Incentivo ao Esporte.

Outras maneiras pelas quais os atletas se beneficiam são o PAAR e o patrocínio pessoal. Contudo, dos três atletas que recebem patrocínio pessoal, um deles é uma bolsa fornecida pelo Governo Federal através de uma iniciativa do COI. Por fim, há o Bolsa Atleta, que é a maior fonte de benefício dos atletas, contudo a mais "instável" de acordo com as narrativas, necessitando ser renovada todo ano. Com isso, compreende-se que o financiamento dos atletas de judô de alto rendimento tem como principal investidor o Governo Federal. Isto porque o PAAR, o Bolsa Atleta e a bolsa do SOI são oferecidos pelo Estado, além disso, os clubes e a CBJ investem a partir de Leis de Incentivo ao Esporte.

Entretanto, apenas o Programa Bolsa Atleta investe em atletas de base e de nível nacional. Os demais programas, como o PAAR e o SOI, fornecem auxílio 
apenas para aqueles que alcançaram a seleção brasileira ou importantes resultados internacionais. Além disso, os clubes ofertam um salário apenas para os atletas de ponta. Por fim, de acordo com os relatos, a CBJ fornece subsídios apenas para atletas convocados para compor a seleção brasileira de judô. Contudo, a confederação é uma das que mais recebe recursos financeiros do Estado. Isto mostra uma tendência da CBJ de focar seu investimento principalmente no alto rendimento. Tais resultados mostram um déficit de investimento em atletas de formação.

Além do investimento na base, outras lacunas devem ser levadas em consideração. Uma delas é o pós-carreira do atleta, no qual, por mais que os relatos afirmem que, somando as fontes de captação financeira, dá para se manter no esporte de alto rendimento, poucos conseguem se planejar para a aposentadoria. Isto é, tanto na preparação financeira quanto profissional ao concluir uma faculdade. Outro fator é o suporte para lesões, que são recorrentes no esporte e fazem com que, atualmente, o atleta perca boa parte de sua renda, dificultando seu retorno à prática.

Através desta pesquisa foi possível entender como tem sido o sistema atual de recursos financeiros para o atleta de alto rendimento do judô. Entretanto, estudos que analisem os subsídios para as categorias de base e formação e estudos com outras modalidades individuais devem ser realizados buscando uma compreensão global do sistema brasileiro de financiamento de atletas.

\section{REFERÊNCIAS}

ALBERTI, Verena. Histórias dentro da História. In: PINSKY, Carla Bassanezi. Fontes Históricas. São Paulo: Contexto, 2008. p. 155-202.

BARDIN, Laurence. Análise de Conteúdo. Lisboa: Edições 70, 1977.

BRASIL. Ministério da Cidadania. Atletas Contemplados. Disponível em: https://www.gov. br/cidadania/pt-br/acoes-e-programas/bolsa-atleta/atletas-contemplados. Acesso em: 26 out. 2020 a.

BRASIL. Ministério da Cidadania. Editais do Bolsa Atleta passarão a ser publicados sempre em janeiro a partir de 2021. Disponível em: https://www.gov.br/cidadania/pt-br/ noticias-e-conteudos/esporte/noticias_esporte/editais-do-bolsa-atleta-passarao-a-serpublicados-sempre-em-janeiro-a-partir-de-2021. Acesso em: 9 nov. 2020b.

BUENO, Luciano. Políticas Públicas do Esporte no Brasil: razões para o predomínio do alto rendimento. 2008. 296 f. Tese (Doutorado em Administração pública e governo) - Escola de administração, Fundação Getúlio Vargas, São Paulo, 2008.

CAMARGO, Philipe Rocha de et al. Conhecendo o programa bolsa-atleta. Inteligência Esportiva, n. 3, p. 38 - 41. Disponível em: http://www.inteligenciaesportiva.ufpr.br/site/index. php/revista-inteligencia-esportival. Acesso em: 9 dez. 2020.

CAREGNATO, Rita Catalina Aquino; MUTTI, Regina. Pesquisa qualitativa: análise de discurso versus análise de conteúdo. Texto \& Contexto Enfermagem, v. 15, n. 4, p. 679-684, 2006. 
CBJ. Confederação Brasileira de Judô celebra 50 anos de fundação. Disponível em: https://cbj.com.br/noticias/6890/confederação-brasileira-de-judô-celebra-50-anos-de-

fundação-.html. Acesso em: 9 nov. 2020a.

CBJ. Links. Disponível em: https://cbj.com.br/links/. Acesso em: 10 nov. 2020 b.

COB. COB repassará montante recorde de $\mathbf{R} \$ 120$ milhões em verbas ordinárias para as modalidades olímpicas em 2020. Disponível em: https://www.cob.org.br/pt/galerias/ noticias/cob-repassara-montante-recorde-de-r-120-milhoes-em-verbas-ordinarias-para-asmodalidades-olimpicas-em-2020/. Publicado em: 30 de outubro de 2019.

CORRÊA, Amanda Jorge et al. Financiamento do esporte olímpico de verão brasileiro: mapeamento inicial do programa "bolsa-atleta" (2005-2011). Pensar a Prática, v. 17, n. 4, out./dez. 2014.

DE BOSSCHER, Veerle et al. A conceptual framework for analysing sports policy factors leading to international sporting success. European Sport Management Quarterly, v. 6, n. 2, p. 185-215, 2006.

DE BOSSCHER, Veerle et al. Explaining international sporting success: an international comparison of elite sport systems and policies in six countries. Sport management Review, v. 12, n. 3, p. 113-136, 2009.

DE BOSSCHER, Veerle et al. Successful Elite Sport Policies: An International Comparison of the Sports. Aachen: Meyer \& Meyer, 2015.

DIAS, Yuri Rafael et al. O judô no programa governamental bolsa-atleta: a distribuição espacial dos bolsistas (2011-2013). Pensar a Prática, v. 19, n. 1, p. 118-129, 2016.

DIGEL, Helmut. The context of talent identification and promotion: A comparison of nations. New Studies in Athletics, v. 17, n. 3/4, p. 13-26, 2002.

GIL, Antônio Carlos (org.). Métodos e técnicas de pesquisa social. 6. ed. São Paulo: Atlas, 2008.

GORNER, Karol et al. Motivational structure of men and women in high performance and elite judo. Ido Movement for Culture, v. 19, n. 3, p. 33-41, 2019.

GREEN, Mick; HOULIHAN, Barrie. Elite sport development: policy learning and political priorities. London: Routledge, 2005.

GUIMARÃES, Adriana Aparecida. Políticas públicas no âmbito do Ministério do Esporte e os planos plurianuais dos governos Fernando Henrique Cardoso, Luiz Inácio Lula da Silva e Dilma Rousseff: Com o orçamento quem ganha o quê, quando e como?. 2017. 204 f. Tese (Doutorado em Ciências Sociais Aplicadas). - Universidade Estadual de Ponta Grossa, Ponta Grossa, 2017.

INSTITUTO REAÇÃO. Sobre o reação. Disponível em: https://institutoreacao.org.br/sobreo-institutol. Acesso em: 27 out. 2020.

KRATZ, Caroline de Andrade et al. Beta-alanine supplementation enhances judo-related performance in highly-trained athletes. Journal of Science and Medicine in Sport, v. 20, p. 403-408, 2017.

KSIAZŻEK, Anna et al. An assessment of diet among high - rank professional judo athletes. Journal of Combat Sports and Martial Arts, v. 5, n. 1, p. 37-41, 2014. 
LAGE, Maria Campos. Utilização do software NVivo em pesquisa qualitativa: uma experiência em EaD. ETD - Educação Temática Digital, v. 12, p. 198-226, 2011.

MACHADO, Paula Carolina; PLAPLER, Hélio. Epidemiological study of Brazilian Judo injuries. Acta Scientific Orthopaedics, v. 2, n. 8, p. 14-22, 2019.

MATIAS, Wagner Barbosa et al. A Lei de Incentivo Fiscal e o (não) direito ao esporte no Brasil. Movimento, v. 21, n. 1, p. 95-110, jan./mar. 2015.

MAZZEI, Leandro Carlos. High-performance Judo: organizational factors influencing the international sporting success. 2015. 149 f. Tese (Doutorado) - Escola de Educação Física e Esporte, Universidade de São Paulo, São Paulo, 2015.

MAZZEI, Leandro Carlos et al. Gestão da Confederação Brasileira de Judô. Revista Intercontinental de Gestão Desportiva, v. 2, n. 1, p. 30-42, jan./jun. 2012.

MORAES E SILVA, Marcelo et al. A configuração do financiamento do governo brasileiro ao esporte de rendimento: apontamentos iniciais. In: MEZZADRI, Fernando Marinho (org.). Políticas Públicas e Esporte. Várzea Paulista - SP: Editora Fontoura, 2014. p. 93-113.

OLIVEIRA, Mauricio Santos; BORTOLETO, Marco Antonio Coelho. Public sports policy : the impact of the athlete scholarship program on Brazilian men's artistic gymnastics. Science of Gymnastics Journal, v. 4, n. 1, p. 5-19, 2012.

PICETSKEI, Caroline Costa et al. Programa de Apoio ao Atleta de Alto Rendimento (PAAR) como uma alternatica para o esporte de alto rendimento. In: CONGRESSO INTERNACIONAL DE EDUCAÇÃO FÍSICA E MOTRICIDADE HUMANA, 6, 2019. São Paulo. Anais.... Campina Grande: Realize Editora, 2019.

PINHEIRO, Maria Claudia et al. Experiências de dor e lesão no desporto feminino. Movimento, v. 17, n. 4, p. 101-121, out./dez. 2011.

POCECCO, Elena et al. Injuries in judo: a systematic literature review including suggestions for prevention. British Journal of Sports Medicine, v. 47, p. 1139-1143, 2013.

QUEIROZ, Diego Alves Ribeiro et al. Produção científica sobre o judô : análise dos artigos, dissertações e teses produzidas no Brasil. Conexões: Educação Física, Esporte e Saúde, v. 18, p. 1-12, 2020.

REDDY, Shalini T. et al. Effect of low-carbohydrate high-protein diets on acid-base balance, stone-forming propensity, and calcium metabolism. American Journal of Kidney Diseases, v. 40 , n. 2, p. 265-274, 2002.

REIS, Fabiana Della Giustina dos; CAPRARO, André Mendes. Judocas brasileiros: um panorama sobre os atletas contemplados pelo programa bolsa-atleta pódio entre os anos de 2013 e 2018. Motrivivência, v. 32, n. 63, p. 01-19, 2020.

ROCHA, Priscila Garcia Marques da; SANTOS, Edvando Souza dos. O abandono da modalidade esportiva na transição da categoria juvenil para adulto: estudo com talentos do atletismo. Revista da Educação Física/UEM, v. 21, n. 1, p. 69-77, 2010.

SOUZA, Giordano Melges de. Atleta Profissional Militar: análise em face da legislação brasileira. 2017. 64 f. Dissertação (Mestrado em Direito Desportivo) - Escola de Direito, Pontifícia Universidade Católia de São Paulo - (PUC-SP), São Paulo, 2017.

STERKOWICZ, Stanislaw et al. The effects of training and creatine malate supplementation during preparation period on physical capacity and special fitness in judo contestants. Journal of the International Society of Sports Nutrition, v. 9, n. 41, p. 1-8, 2012. 
TUBINO, Manoel. O que é esporte. São Paulo: Brasiliense, 1993.

VARGAS, Pauline Iglesias; CAPRARO, André Mendes. O suporte financeiro na trajetória esportiva dos atletas da seleção brasileira de ginástica artística. Research, Society and Development, v. 9, n. 10, 2020. DOI: http://dx.doi.org/10.33448/rsd-v9i10.9089 
Abstract: Judo is a prominent sport in Brazil, partly as a result of governmentprovided financial support. This work describes and analyzes top judo athletes' fundraising strategies and the uses they make of the Athlete Scholarship Program in their careers. Seventeen athletes from Brazil's national judo team were interviewed. Athletes usually benefit from four funding sources - clubs, individual sponsors, the High-Performance Athletes Program (PAAR), and the Athlete Scholarship Program. In addition, the Brazilian Judo Confederation (CBJ) assists with other resources. The study concludes that the main funding sources for athletes are provided by the federal government. High performance athletes are able support themselves, but lower-level athletes are underfunded and lack support to recover from injuries and for their post-career times.

Keywords: Martial arts. Athlete's performance. Professional athletes. Funding.

Resumen: El judo es un deporte destacado en Brasil, y una de las razones de esto es el apoyo financiero que ofrece el país. Por eso, este trabajo tuvo como objetivo describir y analizar las formas de captación de recursos económicos de los deportistas de élite del judo, y detalla la utilización del Programa Bolsa Atleta (Beca Atleta) en sus carreras. Fueron entrevistados 17 deportistas de la selección brasileña de judo. Generalmente, los deportistas se benefician de cuatro fuentes de recursos financieros: club, patrocinios individuales, Programa de Atletas de Alto Rendimiento (PAAR) y Programa Bolsa-Atleta. Además, la Confederación Brasileña de Judo (CBJ) colabora con otros recursos. Se concluyó que las principales fuentes de financiación de los deportistas provienen del gobierno federal. Es posible mantenerse económicamente como deportista de alto rendimiento, sin embargo, existe un déficit en la financiación de los judokas de base, falta de apoyo para la recuperación de lesiones y para la poscarrera del deportista.

Palabras clave: Artes marciales. Desempeño atlético. Deportistas profesionales. Financiación de capital. 


\section{LICENÇA DE USO}

Este é um artigo publicado em acesso aberto (Open Access) sob a licença Creative Commons Atribuição 4.0 Internacional (CC BY 4.0), que permite uso, distribuição e reprodução em qualquer meio, desde que o trabalho original seja corretamente citado. Mais informações em: http://creativecommons.org/licenses/by/4.0

\section{CONFLITO DE INTERESSES}

Os autores declararam que não existe nenhum conflito de interesses neste trabalho.

\section{CONTRIBUIÇÕES AUTORAIS}

Fabiana Della Giustina dos Reis: Conceptualização, Investigação, Metodologia, Redação - rascunho original.

André Mendes Capraro: Conceptualização, Administração do projeto, Supervisão, Redação - revisão e edição.

\section{FINANCIAMENTO}

O presente trabalho foi realizado sem apoio financeiro

\section{ÉTICA DE PESQUISA}

O projeto de pesquisa foi encaminhado e aprovado pelo CEP da Universidade de Brasília, protocolo número 51225615.5.0000.5540.

\section{COMO REFERENCIAR}

REIS, Fabiana Della Giustina dos; CAPRARO, André Mendes . "A gente tem que somar": fontes de captação financeira de atletas da seleção brasileira de judô. Movimento (Porto Alegre), v.27, p.e27043, jan./dez. 2021. Disponível em: https:// seer.ufrgs.br/Movimento/article/view/112306. Acesso em: [dia] [mês abreviado]. [ano]. DOI: https://doi.org/10.22456/1982-8918.112306

\section{RESPONSABILIDADE EDITORIAL}

Alex Branco Fraga*, Elisandro Schultz Wittizorecki*, Ivone Job*, Mauro Myskiw*, Raquel da Silveira*

*Universidade Federal do Rio Grande do Sul, Escola de Educação Física, Fisioterapia e Dança, Porto Alegre, RS, Brasil. 